\title{
Endotracheopulmonary Instillation, Powder for Solution Dosage Form
}

National Cancer Institute

\section{Source}

National Cancer Institute. Endotracheopulmonary Instillation, Powder for Solution

Dosage Form. NCI Thesaurus. Code C149490.

Solid preparation consisting of one or more powders intended to be dissolved in the specified liquid to obtain an endotracheopulmonary instillation solution. 